\title{
Moderators in an Equation: How Organisational Culture and Information System Complexity add Moderating Effects in Theory of Planned Behaviour
}

\author{
Saiyidi Mat Roni ${ }^{*}$, Hadrian Geri Djajadikerta ${ }^{1}$ and Terri Trireksani ${ }^{2}$ \\ ${ }^{1}$ School of Business \& Law, Edith Cowan University, Australia. (mohd.matroni@ecu.edu.au) \\ ${ }^{2}$ Murdoch University, Australia.
}

\begin{abstract}
This paper introduces two moderating variables into an established predictor-criterion relationship in theory of planned behaviour. These were organisational culture and information system complexity (complex). Analyses were made to determine whether these variables were pure or quasi moderating variables which could change a 'true' regression equation, hence the form of predictor-criterion relationships. Using partial-leastsquare structural equation modelling approach, a systematic assessment was made to determine the nature of moderating variables. It was found that culture and complexity were pure moderating variables. These moderating effects however were limited to certain predictor-criterion relationship.
\end{abstract}

Keywords: moderator, theory of planned behaviour, partial least square, structural equation modelling, organisational culture, complexity.

\section{Introduction}

Theory of planned behaviour (TPB) has long been used to explain variety of behaviours in many disciplines. Information system field in particular, is surged with scholarly work to predict human behaviour when working with technology. The work stems from predicting acceptance of information technology to misuse of such system on the basis of TPB. A large number of studies (e.g. Heinze \& Hu, 2009; Jimmieson, Peach, \& White, 2008; Yan \& Sin, 2013) finds that predictors of intention in TPB (i.e. attitude, subjective norms and perceived behaviour control) significantly shape intention, which is the nexus of the theory. In a classic predictor-criterion validation model, the findings reaffirm what has been understood. Others (e.g. Jimmieson et al., 2008; Workman, 2005) however, find the effects of these three predictors are inconsistent. The phenomena lead researchers to look for other explanations for these variations.

Sharma, Durand, and Gur-Arie (1981) suggest variations in predictive efficacy of an independent variable and/or the form of relationship can vary due to systematic influence of other variables. As such, a classic validation model in some instances does not provide sufficient understanding of the phenomenon being studied. That influence comes from interactions of a third factor with the predictor variables - moderating variable.

In the current study, two moderating variables are introduced into TPB equation to examine their moderating effects. The variables are organisational culture (culture) and information system complexity (complexity). The inclusion of moderating variables is important to enhance understanding of the predictor-criterion relationship and to provide further insights into a seemingly established relationship (Walsh, Evanschitzky, \& Wunderlich, 2008). 


\section{Model Formation}

Theory of planned behaviour (TPB) postulates that intention is central to actual behaviour. Intention on the other hand, is affected by three antecedences - attitude (ATT), subjective norm (SN) and perceived behaviour control (PBC). These three predictors can predict intention with a high accuracy across different behaviours (Ajzen, 1991; Armitage \& Conner, 2001).

Attitude defines a degree of favourable or unfavourable evaluation of a person upon a given behaviour, while subjective norm refers to perceived social pressure to perform or not to perform behaviour being studied (Ajzen \& Madden, 1986). Each of these predictors influences intention hence the actual behaviour. In a complete volitional control, a person with positive attitude towards the behaviour and with good perception of important other's evaluation on behaviour (SN) will increase intention and subsequently drive to perform behaviour.

Unlike ATT and SN, perceived behaviour control (PBC) has attracted considerable amount of scholarly attentions. Generally, TPB was introduced by Ajzen (1991) as an answer to improve his prior theory of reason action (TRA). What differentiates TPB and TRA is the inclusion of PBC in TPB to account for factors beyond one's volitional control. PBC however, is argued to compose of two distinct components (Kidwell \& Jewell, 2003) - self-efficacy (internal control) and controllability (external control). This is in spite of Ajzen (2002) conclusion that PBC at its higher order is a single construct "... and the extent to which they (internal and external controls) reflect one or the other is an empirical question (Ajzen, 2002, p. 680)." On a basis of discriminant and convergence factorial empirical test, $\mathrm{PBC}$ in this study is maintained as two distinct components although with the presence of sufficient theoretical commonality between self-efficacy and controllability. This is because PBC in the context of this study is operationalised as perception of control over resources to engage in actual behaviour (PBC-Res) and perception of control over outcome of intended behaviour (PBC-OutC).

In the context of human-computer interaction, complexity of a computer system can affect the nature of predictor-criterion relationship. System complexity (COMPLEX) introduces a relative difficulty level (Thompson, Higgins, \& Howell, 1991) to users, prompting them either to engage in or abandon behaviour. Although similar to the notion of internal and external controls captured by perceived behaviour control, system complexity differs in a way that it specifically measures human-computer interaction presented by the technology. Where the amount of resources (e.g. time, money and effort) to engage in a given behaviour is already captured by PBC-Res, and the severity of subsequent complications following negative behaviour measured by PBC-OutC, complexity introduces another external phenomenon that modifies the intensity of ATT, $\mathrm{SN}$ as well as PBC-Res and PBC-OutC have on intention. Therefore, COMPLEX is said to be moderating the effect of all intention antecedences rather than directly effecting intention.

Similarly, where social pressure is already captured by $\mathrm{SN}$, the environment where the social pressure originates moderates the influence of ATT, SN, PBC-Res and PBC-OutC on INTENT. The environment which is identified as organisational culture (CULTURE) exists independent of SN. CULTURE helps to shape ATT, SN, PBC-Res and PBC-OutC but does not necessarily affect INTENT because intention is a direct result of complex articulation and cognitive assessment of an actor. Therefore, CULTURE interacts with ATT, SN, PBCRes and PBC-OutC in the formation of INTENT.

\section{Moderating Variable}

Moderating variables differ in effects they play on an established predictor-criterion relationship. Intervening and homologiser variables form one category of moderating variable that influence the strength of predictor-criterion relationship; whilst quasi and pure moderating variable affects the form of such relationship (Sharma et al., 1981). In this study, the latter category of moderating variable was tested. This is because quasi and pure moderating variables are both assumed to form interaction effects with the predictor variable, thus changes the form of a well-established predictor-criterion relationship. Despite the fact that quasi moderating 
variable is not considered as moderator within psychometric definition due to an assumption of moderatorpredictor and/or moderator-criterion relatedness, deciding whether this third variable is quasi or pure moderating variable is critical to find theoretical justification based on objective statistical outputs.

In a standard regression equation with a single predictor and a single criterion, a linear relationship is denoted as in equation 1, where criterion $y$ is expressed as a function of constant $a$, regression slope $b$ of predictor $x$ and error $\varepsilon$. This equation is central in the classic validation model.

$$
y=a+b x+\varepsilon
$$

In the classic validation model, theory of planned behaviour (TPB) can be illustrated with intention (INTENT, $y$ ) is affected by attitude (ATT, $x_{1}$ ), subjective norm (SN, $x_{2}$ ), perceived behaviour control over outcome (PBC-OutC, $x_{3}$ ) and perceived behaviour control over resources (PBC-Res, $x_{4}$ ). Using equation 1 above, INTENT (y) can be expressed as in equation 2.

$$
y=a+b_{1} x_{1}+b_{2} x_{2}+b_{3} x_{3}+b_{4} x_{4}+\varepsilon
$$

However, in the interest to illuminate moderating variable effects, equation 3 and 4 were designed and later tested using WarpPLS version 4.0, a component-based structural equation modelling (SEM).

In model 1, CULTURE and COMPLEX were assumed to be pure moderating variables for which interaction between these variables and predictors were tested. Equation 3 was written to capture the effects of these pure moderating variables. Equation 4 was written to define how INTENT was influenced by a proposition that CULTURE and COMPLEX were assumed to be quasi moderating variables. This is illustrated in model

$y=a+b_{1} x_{1}+b_{2} x_{2}+b_{3} x_{3}+b_{4} x_{4}+d_{1} m_{1} x_{1}+d_{2} m_{1} x_{2}+d_{3} m_{1} x_{3}+d_{4} m_{1} x_{4}+d_{5} m_{2} x_{1}+d_{6} m_{2} x_{2}+d_{7} m_{2} x_{3}+d_{8} m_{2} x_{4}+\varepsilon$

$y=a+b_{1} x_{1}+b_{2} x_{2}+b_{3} x_{3}+b_{4} x_{4}+c_{1} m_{1}+c_{2} m_{2}+d_{1} m_{1} x_{1}+d_{2} m_{1} x_{2}+d_{3} m_{1} x_{3}+d_{4} m_{1} x_{4}+d_{5} m_{2} x_{1}+d_{6} m_{2} x_{2}+d_{7} m_{2} x_{3}$

$+d_{8} m_{2} x_{4}+\varepsilon$

\section{Methodology}

A total of 1380 surveys were sent to middle managers of medium size companies in Malaysia. 387 responses were later collected and used for the analysis. This represented $28 \%$ response rate which was acceptable in a survey-based study (see Baruch \& Holtom, 2008; Taskin, 2011).

\subsection{Scale Development}

The latent construct of theory of planned behaviour (TPB) were measured using an instrument adapted from those developed by Chatterjee (2008), Venkatesh, Morris, Gordon, and Davis (2003), Ajzen (n.d.), Ajzen (1991), and Thompson et al. (1991). Specifically, five questions were designed to capture intention (INTENT), three for subjective norm (SN), two for attitude (ATT) and five for perceived behaviour control (PBC), with two measuring perceived control over the outcome of behaviour (PBC-OutC) and three measuring control over resources to perform behaviour (PBC-Res).

All scales were tested for reliability and validity. Cronbach's alpha for all scales were between 0.84 to 0.90 , exceeding 0.7 reliability threshold as suggested by Hair, Black, Babin, Anderson, and Tatham (2006). Convergent validity was confirmed through average variance extracted (AVE) values that exceed minimum cutoff of 0.5 (Fornell \& Larcker, 1981), while discriminant reliability was confirmed with square-root of AVE that exceeded correlation values of the latent variable with other variables (Kock, 2013).

Organisational culture (CULTURE) was measured from four different dimensions using an instrument developed by (Muijen et al., 1999). These dimensions were support (6 items), innovation (6 items), practice (3 items) and performance (6 items). Using WarpPLS, these four dimensions were input into the software as firstorder factors, and later aggregated at a higher order factor to form a second-order latent construct CULTURE. 


\subsection{Data Analysis}

In the interest of this study, only equation 3 and 4 were tested. Equation 3 had sound theoretical backings to include ATT, SN, PBC-Res and PBC-OutC as predictors of INTENT, and CULTURE and COMPLEX as moderating variables. In equation 4 where CULTURE and COMPLEX were 'assumed' to be quasi moderating variables, two additional direct links were drawn, each from CULTURE to INTENT and COMPLEX to INTENT. These links were later checked against recommended effect size thresholds (see Cohen, 1988) to see if they are relevant. Cohen (1988) suggests effect size of .02 or more as small, .15 as medium and .35 as large. Any value lower than .02 is negligible for a practical purpose.

\section{Results and Discussion}

The results supported the theory that organisational culture (CULTURE) and system complexity (COMPLEX) were pure moderating variables. The effects of CULTURE on INTENT $(\beta=.03, p=.28)$, and COMPLEX on INTENT $(\beta=.05, p=.14)$ as in equation 4 (quasi-moderator) were both non-significant. In fact, the effect sizes of both paths were too weak to be considered relevant from a practical standpoint (see Table 1). This is in spite of other model fit and quality indices remain similar in both models.

TABLE I: Model Fit and Quality Indices

\begin{tabular}{lcc}
\hline & Pure moderator & Quasi-moderator \\
\cline { 2 - 3 } Average path coefficient & $0.11, p=.003$ & $0.11, p=.005$ \\
Average $R^{2}$ & $0.81, p<.001$ & $0.82, p<.001$ \\
Average adjusted $R^{2}$ & $0.81, p<.001$ & $0.81, p<.001$ \\
Tenenhaus GoF & 0.75 & 0.75 \\
$R^{2}$ contribution ratio & 0.98 & 0.98 \\
$Q^{2}$ & 0.76 & 0.76 \\
*Effect size of CULTURE-INTENT & Not applicable & 0.003 \\
*Effect size of COMPLEX-INTENT & Not applicable & 0.008 \\
\hline
\end{tabular}

Having established CULTURE and COMPLEX as pure moderating variables, a closer look at path coefficients in model 2 was made. It was found CULTURE significantly moderated ATT-INTENT and SNINTENT relationships but did not exhibit significant moderating effect on PBC-OutC-INTENT nor PBC-ResINTENT relationships. Therefore, organisational culture is a conduit that helps to shape attitude and subjective norm of employees on their intention to engage in dysfunctional behaviour.

System complexity on the other hand, significantly moderated ATT-INTENT relationship but did not affect other predictor-criterion relationships. Based on this result, system complexity is said to be affecting employees' attitude towards their intention to commit dysfunctional behaviour when dealing with information system. In practical sense, adding more application controls to information system will not affect users perceived control over the resources to commit and outcome of negative behaviour, rather it will help to change the attitude of the person towards such behaviour.

From theoretical point of view, choosing which model best represents the 'true' predictor-moderatorcriterion relationship is not a straightforward answer. This is because preference of one model over the other means that certain variables and/or moderating effects have to be dropped or added. Removing a relevant variable introduces a bias on coefficient estimates, while adding an irrelevant variable reduces adjusted $R^{2}$ (Studenmund, 2006; Sykes, 1993). Therefore, it is advisable to fall back to the theory underpinning the model when it is first conceptualised. If the variable has a sound theoretical background, the variable is retained in the model regardless of its statistical (non)significance. However, this decision also has to be based on an improvement of adjusted $R^{2}$ and significant changes in other variables' coefficients when the variable in question is added into the model (see Sharma et al., 1981; Studenmund, 2006; Walsh et al., 2008). 


\section{Conclusion}

The objectives of this paper are two-fold. First, it demonstrates the importance of moderating variables that changes the form of predictor-criterion relationship in a classic validation model. In the case of employee dysfunctional behaviour when dealing with information system, moderating effects of organisational culture and information system complexity were introduced into an established predictor-criterion relationship suggested in theory of planned behaviour.

Second, the paper illustrates that in the presence of a moderating variable with a sound theory supporting it, it is also impetus to test if such moderating variable is quasi or pure moderator. Using PLS-based SEM, this can be achieved by comparing two competing models, one with pure moderating variables and the other with the quasi moderators.

In order to retain or to drop an existing variable, researchers have to fall back to underlying theories supporting such action. From statistical point of view, the decision to drop or to retain a variable depends on significant changes in adjusted $R^{2}$, variables coefficients and the effect size of path coefficient.

\section{References}

[1] Ajzen, I. (1991). The theory of planned behavior. Organizational Behavior and Human Decision Processes, 50(2), 179-211. doi:10.1016/0749-5978(91)90020-t

[2] Ajzen, I. (2002). Perceived Behavioral Control, Self-Efficacy, Locus of Control, and the Theory of Planned Behavior1. Journal of Applied Social Psychology, 32(4), 665-683. doi:10.1111/j.1559-1816.2002.tb00236.x

[3] Ajzen, I. (n.d.). Constructing a Theory of Planned Behaviour Questionnaire. Retrieved from http://people.umass.edu/aizen/pdf/tpb.measurement.pdf

[4] Ajzen, I., \& Madden, T. J. (1986). Prediction of goal-directed behavior: Attitudes, intentions, and perceived behavioral control. Journal of Experimental Social Psychology, 22(5), 453-474. doi:10.1016/0022-1031(86)90045-4

[5] Armitage, C. J., \& Conner, M. (2001). Efficacy of the theory of planned behaviour: A meta-analytic review. The British Journal of Social Psychology, 40, 471-499.

[6] Baruch, Y., \& Holtom, B. C. (2008). Survey response rate levels and trends in organizational research. Human Relations, 61(8), 1139-1160. doi:10.1177/0018726708094863

[7] Chatterjee, S. (2008). Unethical behavior using information technology. (Ph.D. 3370378), Washington State University, United States -- Washington. ABI/INFORM Complete; ProQuest Central; ProQuest Dissertations \& Theses (PQDT) database.

[8] Cohen, J. (1988). Statistical power analysis for the behavioural sciences (2nd ed.). Hillsdale, New Jersey: Lawrence Erlbaum Associates.

[9] Fornell, C., \& Larcker, D. F. (1981). Evaluating structural equation models with unobservable variables and measurement error. JMR, Journal of Marketing Research, 18(1), 39.

[10] Hair, J. F., Black, W. C., Babin, B. J., Anderson, R. E., \& Tatham, R. L. (2006). Multivariate data analysis (6 ed.). New Jersey: Pearson Prentice Hall.

[11] Heinze, N., \& Hu, Q. (2009). Why college undergraduates choose IT: A multi-theoretical perspective. European Journal of Information Systems, 18(5), 462-475.

[12] Jimmieson, N. L., Peach, M., \& White, K. M. (2008). Utilizing the Theory of Planned Behavior to Inform Change Management: An Investigation of Employee Intentions to Support Organizational Change. Journal of Applied Behavioral Science, 44(2), 237 - 262.

[13] Kidwell, B., \& Jewell, R. D. (2003). An examination of perceived behavioral control: Internal and external influences on intention. Psychology and Marketing, 20(7), 625-642. doi:10.1002/mar.10089

[14] Kock, N. (2013). WarpPLS 4.0 User Manual. Loredo, Texas: ScriptWarp Systems. 
[15] Muijen, J. J. v., Koopman, P., Witte, K. D., Cock, G. D., Susanj, Z., Lemoine, C., . . Turnipseed, D. (1999). Organizational Culture: The Focus Questionnaire. European Journal of Work and Organizational Psychology, 8(4), 551-568. doi:10.1080/135943299398168

[16] Sharma, S., Durand, R. M., \& Gur-Arie, O. (1981). identification and analysis of moderator variables. Journal of Marketing Research, 18(August 1981), 291-300.

[17] Studenmund, A. H. (2006). Using econometrics : A practical guide (5 ed.). Boston, Mass.: Pearson /Addison Wesley.

[18] Sykes, A. O. (1993) An introduction to regression analysis. In, Chicago Working Paper in Law \& Economics: University of Chicago.

[19] Taskin, N. (2011). Flexibility and strategic alignment of enterprise resource planning systems with business strategies: An empirical study. (Doctor of Philosophy), University of British Coumbia, Okanagan.

[20] Thompson, R. L., Higgins, C. A., \& Howell, J. M. (1991). Personal computing: Toward a conceptual model of utilization. MIS Quarterly, 15(1), 125-143.

[21] Venkatesh, V., Morris, M. G., Gordon, B. D., \& Davis, F. D. (2003). User Acceptance of Information Technology: Toward a Unified View. MIS Quarterly, 27(3), 425-478.

[22] Walsh, G., Evanschitzky, H., \& Wunderlich, M. (2008). Identification and analysis of moderator variables: Investigating the customer satisfaction-loyalty link. European Journal of Marketing, 42(9/10), 977-1004. doi:http://dx.doi.org/10.1108/03090560810891109

[23] Workman, M. (2005). Expert decision support system use, disuse, and misuse: A study using the theory of planned behavior. Computers in Human Behavior, 21(2), 211-231. doi:10.1016/j.chb.2004.03.011

[24] Yan, Z., \& Sin, K.-f. (2013). Inclusive education: teachers' intentions and behaviour analysed from the viewpoint of the theory of planned behaviour. International Journal of Inclusive Education, 18(1), 72-85. doi:10.1080/13603116.2012.757811 